\title{
ECHOCARDIOGRAPHIC FEATURES IN COPD PATIENTS
}

\section{*Arul Murugan S., Aravind C., Balaji Muruga B, Muthukumarasamy Department of General Medicine, Sri Lakshmi Narayana Institute of Medical Sciences (Affiliated to Bharath University, Chennai), Osudu, Pondicherry-605502}

\begin{abstract}
Background: COPD is one of the common problem in the current world. Significnt number of patients develops corpulmonale during the course of the illness. Aim of this study is to assess the role of echocardiography in detection of corpulmonale early in the course of the illness before an apparent ECG change appears. Materials and Methods: Fifty consecutive COPD patients with normal ECG attended the OPD were included in the study. Various parameters like RVH, Pulmonary artery systolic pressure; RV Strain and LVEF were calculated. Results: The present study finding reveals that among the fifty patients studied twenty-seven patients had normal echocardiogram with respect to the above parameters and nine persons had mildly elevated pulmonary artery pressure with mean value of $35.2 \mathrm{mmHg}$. LV diastolic dysfunction was noticed in three patients and increased LV mass was noticed in one patient among those who had elevated pulmonary artery pressure. Fourteen patients had RV Hypertrophy without pulmonary hypertension. Conclusion: The results showed that patients can have various stages of corpulmonale even with a normal ECG. ECG is not the sensitive test to detect corpulmoale. It is prudent to do ECHO in all the patients with COPD to rule out early corpulmonale.
\end{abstract}

\section{KEY WORDS}

COPD (Chronic Obstructive Pulmonary Disease), LVEF (Left Ventricular Ejection Fraction), LV Mass (Left Ventricular Mass), Pulmonary artery systolic pressure, Right Ventricular Hypertrophy.

\section{INTRODUCTION}

COPD is one of the common problems in India. Most patients develop Corpulmonale late in the course. ECG is commonly used as screening tool to detect corpulmonale. Purpose of this study is to assess the usefulness and cost effectiveness of echocardiography as a screening tool to detect cardiac changes before an apparent ECG changes occur ${ }^{1-3}$.

Cor pulmonale is defined as "hypertrophy of the right ventricle resulting from diseases affecting the function and/or structure of the lungs".by World Health Organization. ${ }^{4}$ The definition says that presence of Right Ventricular Hypertrophy per se defines the cor pulmonale in the non-pulmonary causes for the same. Since left ventricle is the dominating chamber, considerable degree of right ventricular hypertrophy is needed to shift the axis towards the right. Thus, sensitivity of ECG to detect RVH especially in the early stage is low ${ }^{5}$. In a study conducted by Whitman IR among 4062 patients he concluded that current criteria for RVH is insufficient to detect especially in patients with mild $\mathrm{RVH}^{6}$.

\section{MATERIALS AND METHODS}

Fifty consecutive COPD patients who attended outpatient department of Sri Lakshmi Narayana Institute of Medical Sciences with normal ECG have been studied. Patients with associated diseases like Hypertension and diabetes were excluded. Patients with following ECG findings suggestive of Corpulmonale 
were excluded. Electrocardiographic (ECG) abnormalities in cor pulmonale reflect the presence of right ventricular hypertrophy (RVH), RV strain, or underlying pulmonary disease (see the image below). Such ECG changes may include the following Right axis deviation, $\mathrm{R} / \mathrm{S}$ amplitude ratio in $\mathrm{V} 1$ greater than 1 (an increase in anteriorly directed forces may be a sign of posterior infarction), R/S amplitude ratio in V6 less than 1 and $\mathrm{P}$-pulmonale pattern (an increase in $\mathrm{P}$ wave amplitude in leads 2, 3, and $\mathrm{aVF})^{7}$. Toshiba Echo machine was used and echo was performed by trained physician. Parameters assessed were: LVEF (LVEDD² $\operatorname{LVESD}^{2}$ / LVEDD $^{2}$ ), LV Diastolic function, LV Mass (Devereux formulae 1.04 [(LVID + PWT + IVST) $)^{3}-$ LVID $\left.^{3}\right]$ $\tilde{A}-0.8+0.6)$, Pulmonary artery systolic pressure and Right Ventricular Hypertrophy. LVEDD, LVID and LVESD were assessed by M-mode Echocardiography. Pulmonary artery systolic pressure was measured by tricuspid regurgitant jet velocity. ECG and echocardiogram were done by two different persons and interpreted in a double-blind manner.

\section{RESULTS}

Among the fifty patients studied twenty-seven patients had normal echocardiogram with respect to the above parameters. Nine persons had elevated pulmonary artery pressure ranging from $31.6 \mathrm{mmHg}$ to $41 \mathrm{mmHg}$ with mean value of $35.2 \mathrm{mmHg}$. LV diastolic dysfunction was noticed in three patients and increased LV mass was noticed in one patient among those who had elevated pulmonary artery pressure. Fourteen patients had RV Hypertrophy without pulmonary hypertension. LV parameters were normal among the patients without pulmonary hypertension. All fifty patients had normal LV ejection fraction.

\section{DISCUSSION}

Chronic obstructive pulmonary disease (COPD) is associated with a 2-3 times increased rate of incidence of cardiovascular disorders (CVD) which is independent of other risk factors. The main causes of death among COPD patients are of cardiovascular origin. COPD and CVD have two main risk factors in common, like advanced age and smoking. The systemic extension of pulmonary inflammation gives pathogenetic link between the two conditions ${ }^{8}$.
The echocardiography gives a rapid, noninvasive, portable and accurate method to evaluate the left ventricular function, right ventricle function, right ventricular filling pressure, tricuspid regurgitation and valvular function?.

Impairment of pulmonary blood vessels and right ventricular dysfunction complicate the clinical course of COPD and co-relate inversely with survival. In the pulmonary circulation in patients with COPD, significant structural changes occur. Hypoxemia and chronic ventilator insufficiency is associated with early evidence of medial hypertrophy and intimal thickening in the smaller branches of the pulmonary arteries. Along with these pathological changes, pulmonary vasoconstriction arising from the presence of alveolar hypoxemia, pulmonary vascular bed destruction, changes in intrinsic pulmonary vasodilator substances (decrease in prostacyclin synthase), decrease in eNOS (endothelial nitric oxide synthase), and increase in ET1 (endothelin1) leads to remodeling, increase in blood viscosity, and alteration in respiratory mechanics. All of the above-mentioned changes lead to a significant increase in pulmonary vascular resistance, because of which pulmonary hypertension arises. Right ventricular after load increases due to severe Pulmonary Hypertension with a corresponding increase in right ventricular work resulting in uniform right ventricular hypertrophy. In patients with COPD, hypoxic vasoconstriction leads to right ventricular hypertrophy and dilation which leads to development of right heart failure with systemic congestion and inability to adapt to the peripheral demand on exercise.

An increase of pulmonary arterial pressure is found to occur in $20 \%-90 \%$ of patients when measured by right heart catheterization and that worsening airflow obstruction pulmonary hemodynamics worsens with pulmonary hemodynamics. ${ }^{10-15}$ Other studies have shown that an abnormal elevation in mean pulmonary arterial pressure (Ppa) in COPD of $0.4-0.6 \mathrm{mmHg}$ per year which show that Pulmonary Hypertension in COPD progresses slowly and occurs in mild as well as severe forms of disease. ${ }^{16,17}$

The level of Pulmonary Hypertension has a prognostic value in COPD patients, demonstrated by several studies and a high degree of $\mathrm{PH}$ bears a poor prognosis, and this has been observed in COPD patients receiving long-term oxygen therapy. ${ }^{18}$ 
The present study finding reveals that among the fifty patients studied twenty-seven patients had normal echocardiogram with respect to the above parameters and nine persons had elevated pulmonary artery pressure ranging from $31.6 \mathrm{mmHg}$ to $41 \mathrm{mmHg}$ with mean value of $35.2 \mathrm{mmHg}$. LV diastolic dysfunction was noticed in three patients and increased LV mass was noticed in one patient among those who had elevated pulmonary artery pressure. Fourteen patients had RV Hypertrophy without pulmonary hypertension. LV parameters were normal among the patients without pulmonary hypertension. All fifty patients had normal LV ejection fraction.

Some studies indicate that LV function remains normal in COPD patients, while others suggest that LV dysfunction may be present. ${ }^{19,20}$ Abnormal LV function in patients with COPD may be due to factors, such as hypoxemia and acidosis, coronary artery disease(CAD); ventricular interdependence (right ventricle (RV) and LV share a common septum, hence RV dilatation may lead to bulging of the septum into the LV, which would in turn increase LV end-diastolic pressure, decrease venous return, and diminish LV stroke volume and cardiac output (CO) and large swings in intrathoracic pressure (negative pleural pressure) would increase Ppa and diminish LV stroke volume due to ventricular interdependence, negative pleural pressures may also increase LV after load. ${ }^{21}$

| Left ventricular systolic dysfunction (LVSD) in previous studies was present in $4 \%-32 \%$ patients of COPD. ${ }^{22-25}$ LVDD was seen in COPD patients with normal pulmonary arterial pressure and its incidence increased with increase in right ventricular after load. ${ }^{26}$ Left diastolic dysfunction in COPD patients may be due to chronic hypoxemia leading to myocardial relaxation abnormalities, lung hyperinflation and distension, thereby leading to increased stiffness of the parietal pleura and hence the wall of cardiac fossa leading to an extra load on the ventricle, and also due to ventricular interdependence.

In one previous study, LVH was found in $25 \%-60 \%$ patients dying of COPD mostly in patients who also had right ventricular hypertrophy. ${ }^{27}$

\section{CONCLUSION}

Based on this study result, patients may have varying stages of corpulmonale even in the presence of normal ECG. ECG is not a fool proof investigatory modality to rule out corpulmonale. Strict adherence and proper management of COPD is the only way to control progression of corpulmonale. It is prudent to do Echocardiography in all the COPD patients even in those with normal ECG findings to find out corpulmonale in the early stage and plan treatment.

\section{REFERENCES}

1. Adil Shujaat, Abubakr A and Bajwa. Pulmonary Hypertension Secondary to COPD, Pulmonary Medicine. 2012.

2. Gupta NK and Ritesh Kumar Agrawal. Echocardiographic evaluation of heart in chronic obstructive pulmonary disease patient and its co-relation with the severity of disease, Lung India. 2011:28(2); 105-109.

3. Makarevich AE, Valevich VE and Pochtavtsev AU. Evaluation of pulmonary hypertension in COPD patients with diabetes, Advances in Medical Sciences.2007: 52

4. Emmanuel Weitzenblum. Chronic Cor Pulmonale. Heart. 2003: 89(12); 225-230.

5. E. William Hancock, Barbara J. Deal, David M. Mirvis, Peter Okin, Paul Kligfield and Leonard S. Gettes AHA/ACCF/HRS Recommendations for the Standardization and Interpretation of the Electrocardiogram Part V: Electrocardiogram Changes Associated with Cardiac Chamber Hypertrophy. Circulation. March 17, 2009: vol. 119(10); e251-e261.

6. Isaac R. Whitman, Vickas V. Patel, Elsayed Z. Soliman, David A. Bluemke, Amy Praestgaard, Aditya Jain, David Herrington, Joao A. C. Lima, Steven M. Kawut. Validity of the surface electrocardiogram criteria for right ventricular hypertrophy: the MESA-RV Study. Journal of the American College of Cardiology. February 25,2014: Vol. 63, No.7;672-81.

7. Ali A Sovari, Henry H. Ooi Cor Pulmonale Overview of Cor Pulmonale Management.

http://emedicine.medscape.com/article/154062overview. 2014

8. Lusuardi M, Garuti G and Massobrio M. Heart and Lungs in COPD. Close friends in real life - separatein daily medical practice? Monaldi Archives for Chest Disease.2008: 69 1117.

9. Daniels LB, Krummen DE, Blanchard DG. Echocardiography in pulmonary vascular disease. Cardiol Clin. 2004; 22:38399.

10. Weitzenblum E, Hirth C, Ducolone A, Mirhom R, Rasaholinjanahary J, Ehrhart M. Prognostic value of pulmonary artery pressure in chronic COPD. Thorax. 1981; 36:752-8.

11. Weitzenblum E, Sautegeau A, Ehrhart M, Mammosser M, Hirth C, Roegel E. long term course of pulmonary artery 
pressure in chronic COPD. Am Rev Respir Dis. 1984; 130:993-8.

12. Burrows B, Kettel LJ, Niden AH, Rabinowitz M, Diener CF. Patterns of cardiovascular dysfunction in COPD. N Engl J Med. 1972; 286:912-8.

13. Fishman AP. State of the art: Chronic cor pulmonale. Am Rev Respir Dis. 1976; 114:775-94.

14. Pietra G. Pathology of the pulmonary vasculature and heart. In: Cherniack N, editor. COPD. 1996. pp. 21-6.

15. Thabut G, Dauriat G, Stern JB, Logeart D, Lévy A, MarrashChahla R. Pulmonary haemodynamics in advanced COPD candidates for lung volume reduction surgery or lung transplantation. Chest. 2005; 127:1531-6.

16. Weitzenblum E, Sautegeau A, Ehrhart M, Mammosser M, Pelletier A. Long-term oxygen therapy can reverse the progression of pulmonary hypertension in patients with chronic obstructive pulmonary disease. Am Rev Respir Dis. 1985; 131:493-8.

17. Kessler R, Faller M, Weitzenblum E, Chaouat A, Aykut A, Ducolone'A, Natural history of pulmonary hypertension in a series of 131 patients with chronic obstructive pulmonary disease. Am J Respir Crit Care Med. 2001; 164:219-24.

18. Oswald-Mammosser M, Weitzenblum E, Quoix E, Moser G, Chaouat A, Charpentier C. Prognostic factors in COPD patients receiving long-term oxygen therapy. Chest. 1995; 107:1193-8.
19. Murphy ML, Adamson J, Hutcheson F. Left ventricular hypertrophy in patients with chronic bronchitis and emphysema. Ann Intern Med. 1974; 81:307-13.

20. Fluck DC, Chandrasekar RG, Gardner FV. Left ventricular hypertrophy in chronic bronchitis. Br Heart J. 1966; 28:927.

21. Robotham JL, Lixfeld W, Holland L, MacGregor D, Bryan AC, Rabson J. Effects of respiration on cardiac performance. J Appl Physiol. 1978; 44:703-9.

22. Render ML, Weinstein AS, Blaustein AS. Left ventricular dysfunction in deteriorating patients with chronic obstructive pulmonary disease. Chest. 1995; 107:162-8.

23. Vizza CD, Lynch JP, Ochoa LL, Richardson G, Trulock EP. Right and left ventricular dysfunction in patients with severe pulmonary disease. Chest. 1998; 113:576-83.

24. Jardin F, Gueret P, Prost JF, Farcot JC, Ozier Y, Bourdarias JP. Two-dimensional echocardiographic assessment of left ventricular function in chronic obstructive pulmonary disease. Am Rev Respir Dis. 1984; 129:135-42.

25. Louridas G, Patakas D, Stavropoulos C. Left ventricular function in patients with chronic obstructive pulmonary disease. Cardiology. 1981; 67:73-80.

26. Funk GC, Lang I, Schenk P, Valipour A, Hartl S, Burghuber OC. Left Ventricular Diastolic Dysfunction in Patients with COPD in the Presence and Absence of Elevated Pulmonary Arterial Pressure. Chest. 2008; 133:1354-9.

27. Poddar AK, Chakraborti BN, Ghosh JL, Nandy S, Hazra S. Assessment of left ventricular function in patients of COPD: Ind J Tub. 1997; 44:181.
*Corresponding Author: Arul Murugan S Email: drsarulmurugan@yahoo.com 